\title{
ASSESSMENT OF NECK PAIN, LOW BACK PAIN AND DISABILITY IN PATIENTS ISOLATED AT HOME DUE TO MILD-COVID-19: A CROSS-SECTIONAL STUDY
}

\author{
Gülşah Barğı1 ${ }^{1}$ Kubra Ozonay ${ }^{1}$ \\ ${ }^{1}$ Izmir Democracy University, Faculty of Health Sciences, Department of Physiotherapy and Rehabilitation, Izmir, Turkey
}

Address for Correspondence: Gulsah Bargi, PhD, E-mail: gulsahbargi@gmail.com Received: 17.09.2021; Accepted: 15.12.2021; Available Online Date: 27.01.2022

(C) Copyright 2021 by Dokuz Eylül University, Institute of Health Sciences - Available online at https://dergipark.org.tr/en/pub/jbachs

Cite this article as: Bargi G, Ozonay K. Assessment of neck pain, low back pain and disability in patients isolated at home due to mild-COVID-19: a cross-sectional study. J Basic Clin Health Sci 2022; 6: 155-163.

\begin{abstract}
Purpose: Neck pain (NP), low back pain (LBP) and related disability status in patients with COVID-19 have been not known yet. Therefore, pain and related disability status in patients with mild COVID-19 were investigated in current study.

Methods: Patients with mild-COVID-19 ( $n=45,40.64 \pm 17.18$ year) were included in current study. Pain perception (Numeric Rating Scale) and disability status (Neck Disability Index (NDI), Oswestry Disability Index (ODI)) were evaluated remotely on the online forms at pre-COVID-19, isolation, and post-COVID19 periods between 18 February 2021 and 9 May 2021.

Results: NP existed in 9 (20\%) patients (resting: 0.96 \pm 2.29 , activity: $1.02 \pm 2.42$ ) at pre-COVID-19, 16 $(35.6 \%)$ patients (resting: $1.93 \pm 3.02$, activity: $2.27 \pm 3.52$ ) at isolation and $6(13.3 \%)$ patients (resting: $0.62 \pm 1.81$, activity: $0.87 \pm 2.31)$ at post-COVID-19 periods $(\mathrm{p}<0.05)$. LBP existed in $10(22.2 \%)$ patients (resting: $0.69 \pm 1.44$, activity: $0.84 \pm 1.86$ ) at pre-COVID-19, $19(42.2 \%)$ patients (resting: $2.18 \pm 2.95$, activity: $2.31 \pm 3.05)$ at isolation and $6(13.3 \%)$ patients (resting: $0.53 \pm 1.73$, activity: $0.71 \pm 1.98$ ) at postCOVID-19 periods $(p<0.05)$. COVID-19 had a significant effect on increase in NDI and ODI scores $(p<0.05)$.

Conclusion: NP and LBP are caused by pain reported at isolation and post-COVID-19 periods in patients with mild-COVID-19. Even, difference in rate of LBP arises from isolation period. COVID-19 causes increase in both pain perception and disability scores in the patients. Considering acute side effects of COVID-19 on pain perception and disability status during daily living activities, therapeutic approaches (exercise, positioning, etc.) other than only advice of resting at home should be urgently offered to patients according to needs of patients with mild-COVID-19 during home quarantine.
\end{abstract}

Keywords: SARS-CoV-2, COVID-19, low back pain, musculoskeletal pain, neck pain, pain.

\section{INTRODUCTION}

Severe acute respiratory syndrome coronavirus-2 (SARS-CoV-2), which causes new coronavirus disease (COVID-19) pandemic, has afflicted musculoskeletal system since the earliest stage of the disease $(1,2)$. Main symptom of musculoskeletal system related to COVID-19 is pain in muscles and joints (1-5). Pain has been seen since the first days of the disease (3). Prevalence of muscle and/or joint 
pain seen in patients with COVID-19 varies from $10 \%$ to $69.2 \%(1-5)$. Pathophysiology of changes in musculoskeletal system related to COVID-19 has been mainly attributed to two mechanisms. One of the mechanisms is that the virus can enter cells through transmembrane protease serine 2 and angiotensinconverting enzyme 2 located in muscle tissue, cortical bone, and synovium. These tissues are shown as potential region in COVID-19 $(6,7)$. This mechanism is based on studies about SARS-CoV-1 which is highly like SARS-CoV-2 in terms of genetic and pathological characteristics, and its impacts on musculoskeletal system. Because there are not enough studies examining effects of SARS-CoV-2 on musculoskeletal system until today. Negative effect of the SARS-CoV-1 has been reported as a $20 \%$ reduction on body mass within four days following contamination of the infection (8). Moreover, it has been shown that SARS-CoV-1 causes necrosis and atrophy in muscle fibers $(9,10)$. Another mechanism is that musculoskeletal disorders may occur due to cytokine storm. That is, activities of T lymphocytes, macrophages, and endothelial cells and increased inflammatory cytokine levels cause cytokine storm during COVID-19. High serum levels of interleukin-6 and tumor necrosis factor- $\alpha$ also cause pain in the muscles and/or joints during cytokine storm (11-14). Infection, trauma, inflammatory and congenital diseases are among reasons of neck pain (15), which may consist of any problem in structures such as muscle, intervertebral disc, facet joint, ligament, dura, and nerve root in the neck (16). Neck pain adversely affects activities of daily living of individuals such as personal care, lifting, reading, driving, and sleeping. Therefore, neck pain may give rise to disability by restricting individuals functionally (17). However, to our knowledge, no study investigating neck pain and neck pain-related disability in patients with COVID-19 has existed in the literature yet. Low back pain also occurs due to many factors including trauma, harsh working conditions, improper use of body mechanics, weakness in the low back and abdominal muscles, infection, and inflammatory diseases $(18,19)$. Low back pain leads to functional limitation and disability which prevents to perform activities of daily living such as weightlifting, standing, sitting, walking, and traveling (20). As shown, prevalence of low back pain varies from $3.3 \%$ to $33.1 \%$ in patients with COVID-19 $(1,5,21)$. However, to date, low back pain-related disability in patients with COVID-19 has not been shown yet.
Although it has been known that COVID-19 causes low back pain $(1,5,21)$, there is not any knowledge regarding whether COVID-19 leads to neither neck pain nor neck/low back pain-related disability. Therefore, current study was aimed to investigate neck and low back pain and pain-related disability at pre-COVID-19, isolation, and post-COVID-19 periods in patients with mild-COVID-19, who are isolated at home and in the recovery process of COVID- 19 .

\section{METHODS \\ Study design}

Current study was planned as prospective and crosssectional. All patients were evaluated using an online form prepared on Microsoft Forms between 18 February 2021 and 9 May 2021. The online form consisted of specific questions regarding pain and pain-related disability in neck and back regions of body. Primary outcome was pain and secondary outcome was pain-related disability. The online forms were sent to the patients as an e-mail or a message to mobile phones at isolation period and two weeks after isolation period. The first form, which was sent to the patients at isolation period, contained evaluations about pain and disability at two different times that were pre-COVID-19 (one week before isolation) and isolation periods. Pain and disability during isolation period were evaluated towards the end of isolation period. Finally, assessments have been completed at post-COVID-19 (two weeks after isolation) period. The study was approved by İzmir Democracy University Non-Interventional Research Ethics Committee (2021/01-4) on 29 January 2021 and followed principles of Declaration of Helsinki. Informed consents were obtained from all patients.

\section{Study population}

Patients isolated at home due to COVID-19 were included in current study and followed up until final assessments were completed. All patients were reached through announcements made on social media and close circle connections. In preliminary interview, the patients who volunteered to participate in the study were started to be followed up. Inclusion criteria were volunteering to participate in the study, being $\geq 18$ years old, being diagnosed with mildCOVID-19 and followed up by self-isolating at home, having a positive Polymerase Chain Reaction (PCR) test result or being compatible with COVID-19 at $x-$ ray or tomography of lungs if having a negative PCR 
test result, and having a technological device such as smartphone, computer, or laptop. Exclusion criteria were being diagnosed with COVID-19 and healed without follow-up by self-isolation at home, being pregnant, or having psychiatric illnesses, severe cognitive impairments, musculoskeletal disorders, or problems except for COVID-19.

\section{Pain evaluation}

Presence and intensity of pain during resting and activities were evaluated in neck and low back regions of the patients. Pain intensity was also measured using Numeric Pain Rating Scale $(22,23)$. This valid and reliable scale was scored from 0 (no pain) to 10 (worst pain as possible) $(22,23)$.

\section{Neck pain-related disability}

Neck pain-related disability was evaluated using Turkish version of Neck Disability Index (24). This reliable and valid index (25) consists of 10 questions about pain intensity, personal care, lifting, reading, headaches, concentration, work, driving, sleeping, and recreation. During isolation period, the questions about work and driving were removed from the index since the patients stayed at home due to isolation. However, even if one or more questions are not applicable in Neck Disability Index, this index can be used because the total score is expressed as a percentage. Other questions are scored from 0 (no disability) to 5 (complete disability). Maximum total score is 50 points which is expressed as a percentage. Higher scores demonstrate higher neck pain-related disability (25).

\section{Low back pain-related disability}

Low back pain-related disability was evaluated using Turkish version of Oswestry Disability Index version 2.0 (26). This reliable and valid index (20) consists of 10 questions about pain intensity, personal care, lifting, walking, sitting, standing, sleeping, sex life, social life, and traveling. Since patients could not leave their houses at isolation period, the questions about social life and traveling were removed from the index. However, even if one or more questions are not applicable in the index, this index can be used because the total score is expressed as a percentage. Each question has 6 answers and is scored from 0 (no disability) to 5 (complete disability). The highest score obtained from the index is 50 that is expressed as a percentage. Higher scores demonstrate higher low back pain-related disability (20).

\section{Statistical analyzes}

Sample size for one group was calculated using Raosoft sample size calculator (27). Based on the estimated population $(n=91)$ and response distribution (3.3\%), sample size for current study was found as at least 33 patients along with a confidence level of $95 \%$ and a margin of error of $5 \%$ (21). Windows-based SPSS 15.0 statistical analysis program (SPSS Inc., USA) was used to conduct analyses. Visual (histograms, probability plots, etc.) and analytical methods (Shapiro-Wilk's test) were used to determine whether variables were normally distributed or not. Descriptive analyzes were expressed as mean (x), standard deviation (SD), mean ranks, minimum (min), maximum (max), frequency $(n)$ and percentage (\%). The Cochrane's $Q$ test was used to compare rates of neck and low back pain at all periods which were presented as frequencies $(n)$ and percentages (\%). Level of significance was set to $p<0.05$. For pairwise comparisons, McNemar test was used, and the overall type- 1 error level was limited at $p=0.017$ using Bonferroni correction. Friedman tests were conducted to test a significant change in numerical variables of pre-COVID-19, isolation, and postCOVID-19 periods. Level of significance was set to $p<0.05$. For pairwise comparisons, Wilcoxon test was used, and the overall type-1 error level was limited at $p=0.017$ using Bonferroni correction.

\section{RESULTS}

Out of 95 patients, only 45 could be included in the study (Figure 1). Demographic characteristics of these patients were shown in Table 1.

\section{Presence of pain in neck and low back regions}

Nine (20\%) patients at pre-COVID-19 period, 16 (35.6\%) patients at isolation period and $6(13.3 \%)$ patients at post-COVID-19 period had complaint of neck pain (Figure 2, Table 2, $\mathrm{p}<0.05$ ). Significant difference between three periods resulted from difference in rates of neck pain reported at isolation and post-COVID-19 period (Table $2, p<0.05$ ).

Ten $(22.2 \%)$ patients at pre-COVID-19 period, 19 $(42.2 \%)$ patients at isolation period and $6(13.3 \%)$ patients at post-COVID-19 period had complaint of low back pain (Figure 2, Table 2, p<0.05). Significant 


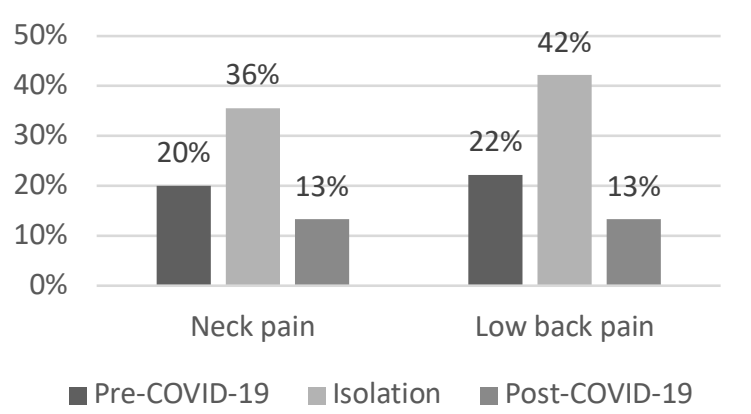

Figure 2. Change in rates of neck and low back pain from pre-COVID-19 period to post-COVID-19 period.

difference between three periods resulted from difference in rates of low back pain reported at isolation and post-COVID-19 period and this difference also started to emerge from isolation period (Table 2, $\mathrm{p}<0.05$ ).

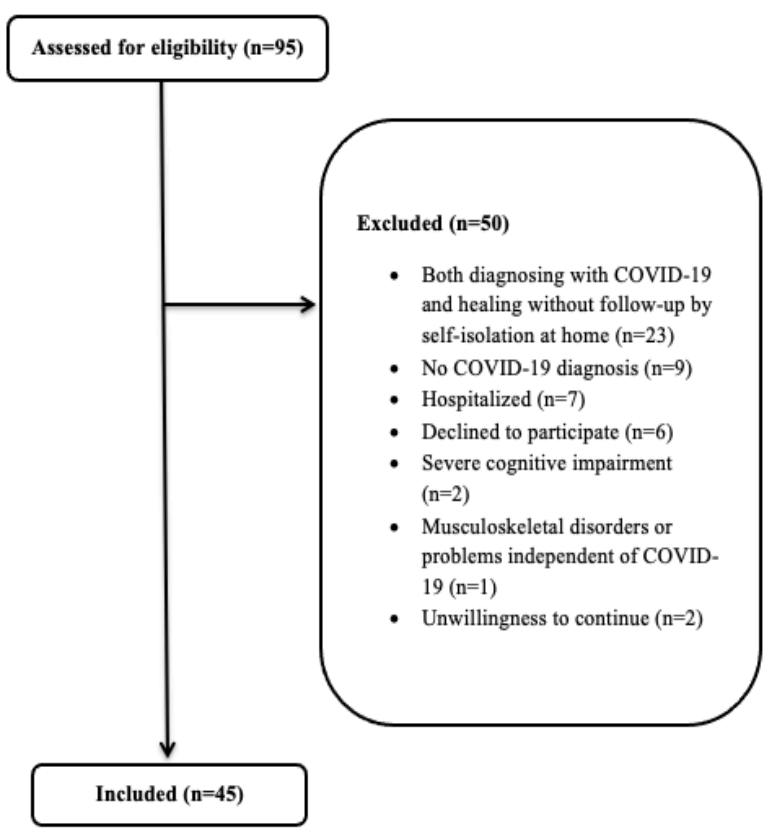

Figure 1. Flow diagram of the study.

\section{Intensity of pain in neck and low back regions}

Significant difference between three periods resulted from difference in intensity of rest and activity neck and low back pain reported at pre-COVID-19 and isolation periods along with isolation and postCOVID-19 periods. In other words, COVID-19 had a significant impact on increase in intensity of rest and activity neck and low back pain (Figure 3, Table 2, $\mathrm{p}<0.05)$.

\section{Neck and low back pain-related disability}

Significant difference between three periods resulted from difference in neck and low back pain-related disability scores reported at isolation and postCOVID-19 periods. That is, COVID-19 had a significant effect on increase in NDI and ODI scores (Figure 4, Table 2, $p<0.05$ ).

\section{DISCUSSION}

Current study demonstrates substantial findings about negative impact of COVID-19 on both neck and low back pain and pain-related disability that is firstly shown in the literature, to our knowledge. Firstly, presence of neck and low back pain seen in patients with mild-COVID-19 is commonly caused by pain reported at isolation and post-COVID-19 periods. Secondly, intensity of neck and low back pain increases due to COVID-19. Finally, COVID-19 also has an increasing effect on pain-related disability in neck and low back regions.

It is thought that COVID-19 causes muscle and joint pain in patients with COVID-19 (6,7,11-14). All our remarkable findings support this notion. Moreover, in current study planned as prospective and crosssectional, $62.2 \%, 64.4 \%$ and $73.3 \%$ of patients with mild-COVID-19 had muscle pain, joint pain, and debility and/or fatigue which were symptoms accompanying COVID-19. Prevalence of neck and low back pain of our patients were respectively $35.6 \%$ and $42.2 \%$ at isolation period which is commonly caused by pain reported at isolation and post-COVID19 periods. COVID-19 increased intensity and related disability of neck and low back pain, too. To provide an effective and comprehensive treatment approach, common neurological and musculoskeletal features of COVID-19 were investigated in a meta-analysis at early period of COVID-19 pandemic (1). Compared to our results, lower prevalence for myalgia (19\%) and low back pain (10\%) in adult populations with COVID19 was revealed in this study (1). This difference may have resulted from inclusion of patients with both critical and non-critical conditions in study of Abdullahi et al. (1). Goyal et al. (4) retrospectively prescribed the first hospitalized patients with COVID19 via electronic health records. Myalgias (23.8\%) were one of the most common symptoms 
Table 1. Baseline demographic characteristics of patients with COVID-19

\begin{tabular}{|c|c|}
\hline & $\begin{array}{l}\text { Patients with COVID-19 } \\
(n=45)\end{array}$ \\
\hline Characteristics & $\mathrm{x} \pm \mathrm{SD} / \mathrm{n}(\%)$ \\
\hline Age (year) & $40.64 \pm 17.18$ \\
\hline Male/female & $11(24.4 \%) / 34(75.6 \%)$ \\
\hline Weight (kg) & $68.13 \pm 11.76$ \\
\hline Height $(\mathrm{m})$ & $1.65 \pm 0.10$ \\
\hline Body mass index $\left(\mathrm{kg} / \mathrm{m}^{2}\right)$ & $25.07 \pm 4.40$ \\
\hline Presence of symptoms accompanying COVID-19 & $40(88.9 \%)$ \\
\hline Fever & $17(37.8 \%)$ \\
\hline Debility and/or fatigue & $33(73.3 \%)$ \\
\hline Cough & $25(55.6 \%)$ \\
\hline Shortness of breath & $5(11.1 \%)$ \\
\hline Headache & $25(55.6 \%)$ \\
\hline Muscle pain & $28(62.2 \%)$ \\
\hline Joint pain & $29(64.4 \%)$ \\
\hline Gastrointestinal complaints & $16(35.6 \%)$ \\
\hline
\end{tabular}

Kg: Kilogram, m: Meter, COVID-19: New coronavirus disease 2019.

Descriptive analyses were presented using $\mathrm{x} \pm \mathrm{SD}$ (mean \pm standard deviation), $\mathrm{n}$ (frequency) and \% (percentage).

accompanying COVID-19 infection (4) which is also lower than our result. Like the study of Goyal et al. (4), another retrospective study conducted by Qian et al. (21) presented early results of patients who were admitted to hospitals due to COVID-19. Lower prevalence for myalgia $(5.49 \%)$ and fatigue $(43.96 \%)$ was in question in patients with COVID-19 based on this early retrospective results (21) compared to ours. These differences may have resulted from the inclusion of more male, older and hospitalized patients in the studies of Goyal et al. (4) and Qian et al. (21). As risk factors for COVID-19 including male gender, older age, and/or having chronical diseases increase, mortality and morbidity rates related to COVID-19 increase (28). Primary symptoms experienced by these hospitalized patients such as fever, cough, nausea, vomiting, dyspnea, headaches, expectoration, hemoptysis, muscle pain, fatigue, diarrhea, and myocarditis also vary in this situation (28). Moreover, our study design was prospective in contrast to these studies $(4,21)$ which may also have affected the higher results of our study. In parallel of our results, Lechien et al. (29) reported that approximately $60 \%$ of patients with mild-to-moderate COVID-19 had myalgia, one of the most prevalent symptoms of COVID-19 infection. Approximately $30 \%$ of these patients had arthralgia (29) which is lower than our results. It may have resulted from inclusion of relatively younger patients in the study of Lechien et al. (29) compared to our results. Based on all these results, it can be said that musculoskeletal pain is more common in patients with mild-COVID-19 and increases due to COVID-19 infection. Therefore, a comprehensive treatment approach including rehabilitative modalities (relaxation exercises, positioning, etc.) should be considered in these patients. Effectiveness of these modalities in patients with COVID-19 should be investigated, as well.

On the other hand, to evaluate the pain considered as an early sign of COVID-19 infection, Murat et al. (5) conducted a retrospective study on hospitalized and discharged patients with COVID-19. Pain (69.3\%) and fatigue $(76.6 \%)$ were among complaints of these patients. Main complaint of especially $46.6 \%$ of these patients was pain that was started about 2 days before admission. Pain, which was reported by the patients as the main complaint, was frequently observed as myalgia/arthralgia (69.2\%) and low back pain $(33.1 \%)$ in the study of Murat et al. (5). Rate of low back pain in the study of Murat et al. (5) is relatively lower than our results. Karaarslan et al. (30) prospectively investigated rheumatic and musculoskeletal symptoms in patients with COVID-19 after discharge by phone interviews, as well. In line with our results except for rate of neck pain $(35.6 \%)$ at isolation period, Karaarslan et al. (30) demonstrated that $92.3 \%$ of patients with COVID-19 reported musculoskeletal symptoms including fatigue $(87.3 \%)$, myalgia $(63.3 \%)$, arthralgia $(59.3 \%)$, low back pain $(44.7 \%)$, and neck pain $(26.7 \%)$ at hospitalization period. At 2-week after hospitalization, $72.7 \%$ of patients with COVID-19 in the study of Karaarslan et al. (30) reported musculoskeletal symptoms including fatigue (64\%), myalgia $(36.7 \%)$, arthralgia (35\%), low back pain $(24.3 \%)$, and neck pain $(15.7 \%)$ which is relatively higher than our 
results related to rate of neck and low back pain $(13.3 \%)$ at post-COVID-19 period. At 1-month after hospitalization, $56.3 \%$ of these patients with COVID19 reported same musculoskeletal symptom including fatigue $(44.3 \%)$, myalgia (21\%), arthralgia $(22 \%)$, low back pain $(16.3 \%)$, and neck pain $(10.3 \%)$. This study provides valuable knowledge about diminished but persisted musculoskeletal symptoms

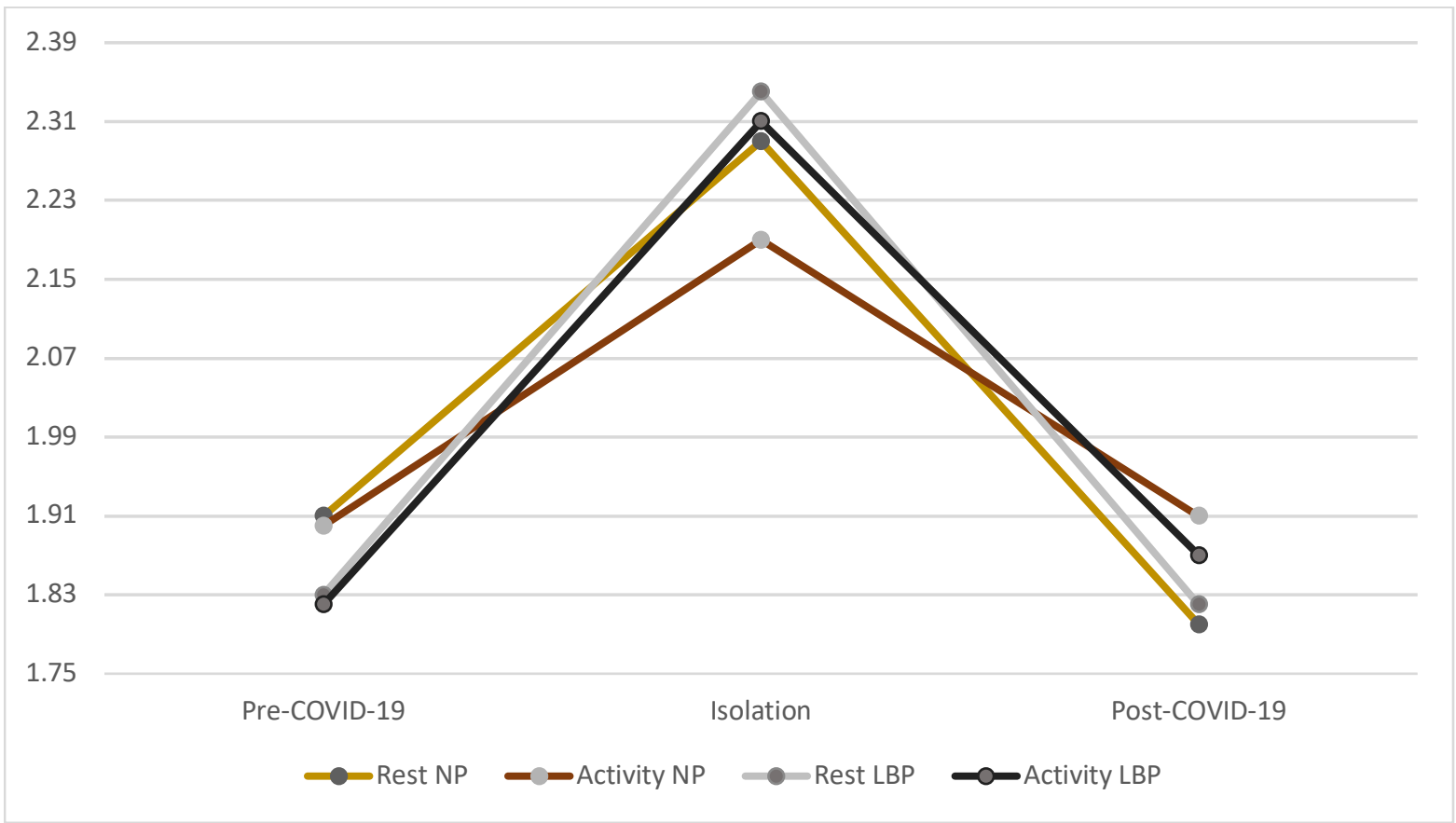

Figure 3. Change in intensity of neck pain (NP) and low back pain (LBP) from pre-COVID-19 period to post-COVID-19 period.

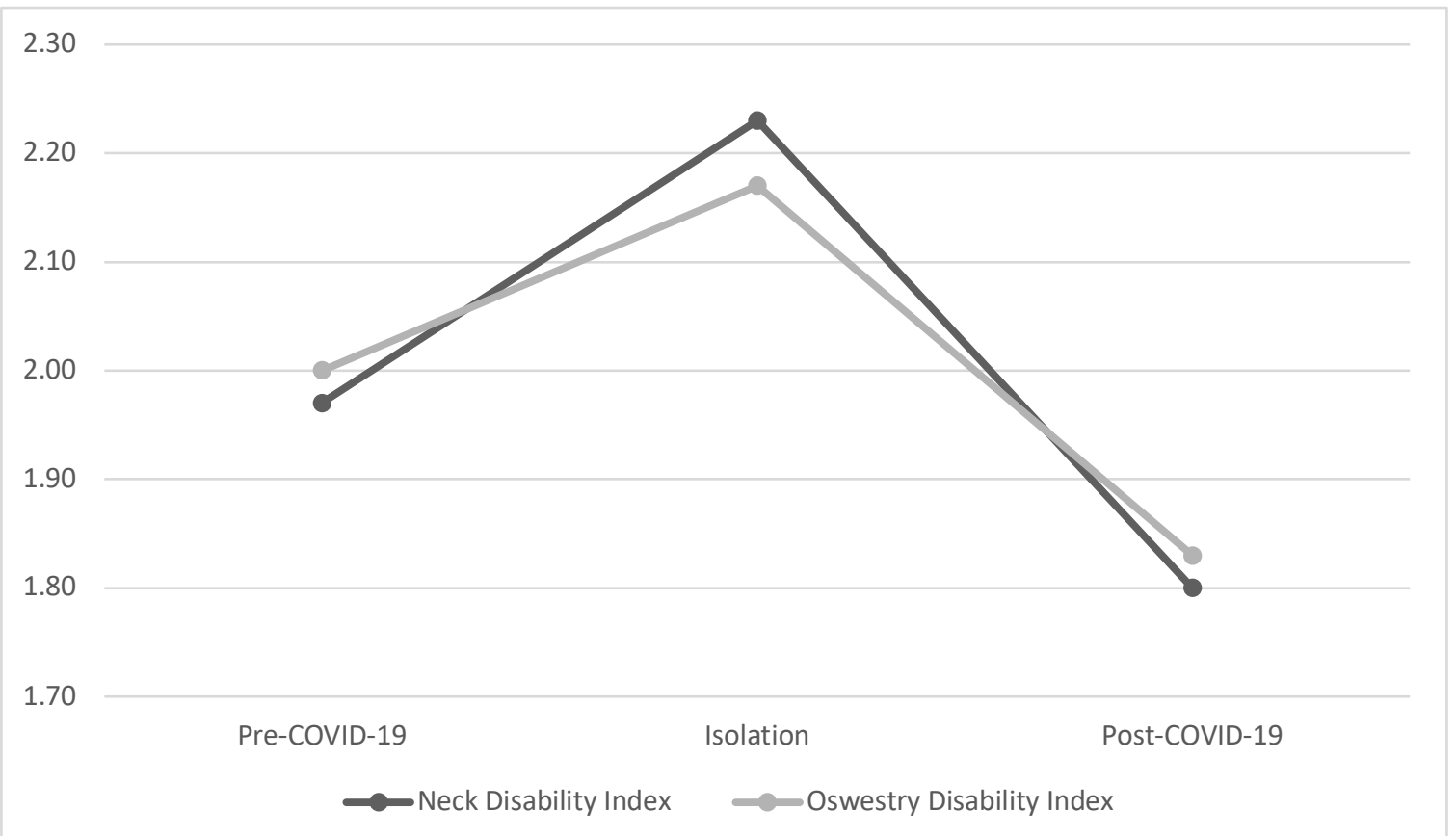

Figure 4. Change in Neck Disability Index and Oswestry Disability Index scores from pre-COVID-19 period to post-COVID-19 period. 
Table 2. Comparison of pain and disability outcomes at pre-COVID-19, isolation, and post-COVID-19 periods in patients with COVID-19

\begin{tabular}{|c|c|c|c|c|c|c|c|}
\hline & $\begin{array}{l}\text { Pre-COVID- } \\
19(n=45)\end{array}$ & $\begin{array}{l}\text { Isolation } \\
(n=45)\end{array}$ & $\begin{array}{l}\text { Post-COVID- } \\
19(n=45)\end{array}$ & $\begin{array}{l}\text { Comparison } \\
\text { of pre- } \\
\text { COVID-19 } \\
\text { and isolation } \\
\text { periods }\end{array}$ & $\begin{array}{l}\text { Comparison } \\
\text { of isolation } \\
\text { and post- } \\
\text { COVID-19 } \\
\text { periods }\end{array}$ & $\begin{array}{l}\text { Comparison } \\
\text { of pre- and } \\
\text { post-COVID- } \\
19 \text { periods }\end{array}$ & $\begin{array}{l}\text { Comparison } \\
\text { of all periods }\end{array}$ \\
\hline & $\begin{array}{l}\mathrm{x} \pm \mathrm{SD} / \text { mean } \\
\text { rank } \\
(\min -\mathrm{max})\end{array}$ & $\begin{array}{l}\mathrm{x} \pm \mathrm{SD} / \text { mean } \\
\text { rank } \\
\text { (min-max) }\end{array}$ & $\begin{array}{l}\mathrm{x} \pm \mathrm{SD} / \text { mean } \\
\text { rank } \\
\text { (min-max) }\end{array}$ & P & P & $\mathbf{p}$ & $\mathbf{p}$ \\
\hline \multicolumn{8}{|c|}{ Presence of pain (n (\%)) } \\
\hline NP & $9(20 \%)$ & $16(35.6 \%)$ & $6(13.3 \%)$ & 0.039 & $0.002^{* *}$ & 0.508 & $0.004^{*}$ \\
\hline LBP & $10(22.2 \%)$ & $19(42.2 \%)$ & $6(13.3 \%)$ & $0.013^{\star *}$ & $0.001^{\star *}$ & 0.219 & $<0.001^{*}$ \\
\hline \multicolumn{8}{|c|}{ Intensity of pain (NRS, $0-10$ ) } \\
\hline Rest NP & $\begin{array}{l}0.96 \pm 2.29 / \\
1.91(0-10)\end{array}$ & $\begin{array}{l}1.93 \pm 3.02 / \\
2.29(0-10)\end{array}$ & $\begin{array}{l}0.62 \pm 1.81 / \\
1.8(0-7)\end{array}$ & $0.009^{\# \#}$ & $0.001^{\# \#}$ & 0.592 & $<0.001^{\#}$ \\
\hline Activity NP & $\begin{array}{l}1.02 \pm 2.42 / \\
1.9(0-10)\end{array}$ & $\begin{array}{l}2.27 \pm 3.52 / \\
2.19(0-10)\end{array}$ & $\begin{array}{l}0.87 \pm 2.31 / \\
1.91(0-8)\end{array}$ & $0.013^{\# \#}$ & $0.006^{\#}$ & 0.906 & $0.017^{\#}$ \\
\hline Rest LBP & $\begin{array}{l}0.69 \pm 1.14 / \\
1.83(0-5)\end{array}$ & $\begin{array}{l}2.18 \pm 2.95 / \\
2.34(0-8)\end{array}$ & $\begin{array}{l}0.53 \pm 1.73 / \\
1.82(0-7)\end{array}$ & $0.001^{\# \#}$ & $0.001^{\# \#}$ & 0.398 & $<0.001^{\#}$ \\
\hline Activity LBP & $\begin{array}{l}0.84 \pm 1.86 / \\
1.82(0-7)\end{array}$ & $\begin{array}{l}2.31 \pm 3.05 / \\
2.31(0-9)\end{array}$ & $\begin{array}{l}0.71 \pm 1.98 / \\
1.87(0-9)\end{array}$ & $0.002^{\# \#}$ & $0.002^{\# \#}$ & 0.571 & $<0.001^{\#}$ \\
\hline \multicolumn{8}{|c|}{ Disability (0-100\%) } \\
\hline NDI & $\begin{array}{l}3.78 \pm 8.32 / \\
1.97(0-31)\end{array}$ & $\begin{array}{l}7.07 \pm 14.38 / \\
2.23(0-78)\end{array}$ & $\begin{array}{l}1.71 \pm 5.24 / \\
1.8(0-29)\end{array}$ & 0.093 & $0.002^{\#}$ & 0.155 & $0.001^{\#}$ \\
\hline ODI & $\begin{array}{l}3.11 \pm 6.37 / \\
2(0-26)\end{array}$ & $\begin{array}{l}6.96 \pm 15.18 / \\
2.17(0-80)\end{array}$ & $\begin{array}{l}1.84 \pm 5.33 / \\
1.83(0-27)\end{array}$ & 0.131 & $0.011^{\# \#}$ & 0.202 & $0.030^{\#}$ \\
\hline
\end{tabular}

NP: Neck pain, LBP: Low back pain, NRS: Numeric Rating Scale, NDI: Neck Disability Index, ODI: Oswestry Disability Index. Descriptive analyses were presented using $n$ (frequency), \% (percentage), $x \pm S D$ (mean \pm standard deviation), mean ranks for difference between related samples, min (minimum) and max (maximum). Cochran $Q$ test ${ }^{*} p<0.05, M c N e m a r$ test ${ }^{* *} p<0.017$. Friedman test ${ }^{\#} p<0.05$, Wilcoxon test ${ }^{\# \#} p<0.017$.

including fatigue, myalgia, arthralgia, neck pain, and low back pain during from hospitalization because of COVID-19 to 1 month after hospitalization. However, this study of Karaarslan et al. (30) did not include nonhospitalized patients with COVID-19. Similarly, Şahin et al. (31) conducted a retrospective study on patients with COVID-19 after discharge via phone call and evaluated severity and body region of pain in these patients. Out of all patients, $74.3 \%$ had mild-COVID$19,23.3 \%$ had moderate-COVID-19 and $2.4 \%$ had severe-COVID-19. Based on the main results of Şahin et al. (31), intensity of pain during COVID-19 was higher than intensity of pain at pre-COVID-19 and post-COVID-19 periods in line with our results. Moreover, neck and back regions at pre-COVID-19 period and head and limbs during COVID-19 were most frequent painful areas. Neck pain existed before (30.6\%, median of intensity: 4$)$, during $(46.6 \%$, median of intensity: 5$)$ and after (36.6\%, median of intensity: 4) COVID-19 all of which are higher values than pain intensity and rates of our patients. Intensity of neck pain was considerably caused by difference between before and during COVID-19 in line with our results. Unfortunately, it has been stated that the pain can continue at post-COVID-19 period. Another study revealed that COVID-19 infection was related with higher prevalence of de novo chronic pain, chronic daily headache, and new-onset pain in survivors with COVID-19 compared to control patients (32). This cross-sectional study was conducted via phone interviews in the patients discharged from the hospital after COVID-19 and non-COVID-19 patients. While 
patients with COVID-19 had lower pain compared to controls before hospitalization ( $10.9 \%$ versus $42.5 \%$ ), these patients had higher de novo pain compared to controls during hospitalization $(65.2 \%$ versus $11 \%)$ in consistent with our results. By $19.6 \%$ of patients with COVID-19 also had higher new-onset chronic pain compared to controls (1.4\%). A retrospective study of Wang et al. (33) showed that out of 90 severe/critically severe patients with COVID-19, 53 had various degrees of neurologic symptoms including fatigue $(n=33)$ and neck pain $(n=1)$. Wang et al. (33) also specified these symptoms were uncommon in patients with severe-COVID-19.

As seen in all studies, the pain can be considered as an early sign of COVID-19. Because the pain emerges due to COVID-19 that is intensified during active COVID-19 period. Although the pain reduces after COVID-19, it continues and becomes chronic. Therefore, the pain related to COVID-19 is undeniable and cannot be ignored. Regardless of the severity of COVID-19, the pain should be evaluated as early as possible in all patients with COVID-19 but especially in mild and moderate COVID-19. The pain can be also alleviated with various appropriate methods other than medication which should be also investigated by further studies.

\section{Limitations}

In our study, we tried to create the most appropriate inclusion and exclusion criteria that would appropriately reveal our hypothesis to deal with some biases arising from the nature of the study. However, some patients hesitated to share some information about themselves with us remotely, such as PCR test, $x$-ray, or tomography results of the lungs. Our main limitation was therefore that our study was conducted remotely due to active virus load and home quarantine. For these reasons, considering willingness to participate in the study, we had to exclude some patients who were declined to participate in the study, unwillingness to continue to the study after pre-interview or stated that there was no diagnosis of COVID-19.

\section{CONCLUSION}

In present study, it was concluded that prevalence and intensity of neck and low back pain and painrelated disability increased during isolation period in patients diagnosed with COVID-19. Moreover, pain and related-disability decreased but continued in process of COVID-19 recovery. Therefore, these patients with mild-COVID-19 should be evaluated and followed in the basis of their needs, pain, and disability. Relaxing approaches such as positioning, exercise, mobilization, and/or heat agents may be offered for neck and low back pain of these patients during isolation and post-COVID-19 periods. Further studies investigating effectiveness of these approaches are needed.

Acknowledgments: Material in this manuscript previously presented as an oral presentation on 8-10 April 2021, at Burdur, at the $4^{\text {th }}$ International Health Sciences and Life Congress.

Author contributions: Conception, design, supervision, fundings, materials, data collection and/or processing, analysis and/or interpretation, literature review, writer, and critical review were performed by both Gülşah Barğı and Kubra Ozonay.

Conflict of Interest: No conflict of interest was declared by the authors.

Ethical Approval: The study was approved by Izmir Democracy University Non-Interventional Research Ethics Committee (2021/01-4) on 29 January 2021.

Peer-review: Externally peer-reviewed.

\section{REFERENCES}

1. Abdullahi A, Acaroz Candan S, Abba MA, et al. Neurological and musculoskeletal features of COVID-19: a systematic review and metaanalysis. Front Neurol 2020;11:687.

2. Cipollaro L, Giordano L, Padulo J, Oliva F, Maffuli $\mathrm{N}$. Musculoskeletal symptoms in SARS-CoV-2 (COVID-19) patients. J Orthop Surg Res 2020;15(1):178.

3. Guan WJ, Ni ZY, Hu Y, et al. Clinical characteristics of coronavirus disease 2019 in China. N Engl J Med 2020;382(18):1708-1720.

4. Goyal P, Choi JJ, Pinheiro LC, et al. Clinical characteristics of Covid-19 in New York City. N Engl J Med 2020;382(24):2372-2374.

5. Murat S, Dogruoz Karatekin B, Icagasioglu A, Ulasoglu $C$, İçten $S$, Incealtin $O$. Clinical presentations of pain in patients with COVID-19 infection. Ir J Med Sci 2020;1-5.

6. Disser NP, De Micheli AJ, Schonk MM, et al. Musculoskeletal Consequences of COVID-19. J Bone Joint Surg Am 2020;102(14):1197-1204.

7. Srinivasan $S$, Cui $H$, Gao Z, et al. Structural Genomics of SARS-CoV-2 Indicates Evolutionary Conserved Functional Regions of Viral Proteins. Viruses 2020;12(4):360.

8. McCray Jr PB, Pewe L, Wohlford-Lenane C, et al. Lethal infection of K18-hACE2 mice infected with severe acute respiratory syndrome coronavirus. J Virol 2007;81(2):813-821. 
9. Ding $\mathrm{Y}$, Wang $\mathrm{H}$, Shen $\mathrm{H}$, et al. The clinical pathology of severe acute respiratory syndrome (SARS): a report from China. J Pathol 2003;200(3):282-289.

10. Hsiao CH, Chang MF, Hsueh PR, Su IJ. Immunohistochemical study of severe acute respiratory syndrome-associated coronavirus in tissue sections of patients. J Formos Med Assoc 2005;104(3):150-156.

11. Nakamura K, Saito K, Hara $Y$, et al. Severe epidemic myalgia with an elevated level of serum interleukin- 6 caused by human parechovirus type 3: a case report and brief review of the literature. BMC Infect Dis 2018;18(1):381.

12. Marks M, Marks JL. Viral arthritis. Clin Med (Lond) 2016;16(2):129-134.

13. Kaiser L, Fritz RS, Straus SE, Gubareva L, Hayden FG. Symptom pathogenesis during acute influenza: interleukin-6 and other cytokine responses. J Med Virol 2001;64(3):262-268.

14. Misra DP, Agarwal V, Gasparyan AY, Zimba O. Rheumatologists' perspective on coronavirus disease 19 (COVID-19) and potential therapeutic targets. Clin Rheumatol 2020;39(7):2055-2062.

15. Binder $A$. The diagnosis and treatment of nonspecific neck pain and whiplash. Eura Medicophys 2007;43(1):79-89.

16. Borghouts JAJ, Koes BW, Bouter LM. The clinical course and prognostic factors of non-specific neck pain: a systematic review. Pain 1998;77(1):1-13.

17. Luo X, Edwards CL, Richardson W, Hey L. Relationship of clinical, psychologic, and individual factors with the functional status of neck pain patients. Value Health 2004;7(1):6169.

18. Karababa AO. Epidemiology of Low Back Pain. Turkiye Klinikleri J Neurosurg-Special Topics. 2010;3(1):1-7.

19. Urquhart DM, Zheng $Y$, Cheng AC, et al. Could low grade bacterial infection contribute to low back pain? A systematic review. BMC Med 2015;13:13.

20. Fairbank JC, Pynsent PB. The Oswestry disability index. Spine (Phila $\mathrm{Pa}$ 1976) 2000;25(22):2940-2952.

21. Qian GQ, Yang NB, Ding F, et al. Epidemiologic and clinical characteristics of 91 hospitalized patients with COVID-19 in Zhejiang, China: a retrospective, multi-centre case series. QJM 2020;113(7):474-481.
22. McCaffery M, Beebe A. Pain: Clinical Manual for Nursing Practice. St. Louis; MO: Mosby; 1989.

23. Cleland JA, Childs JD, Whitman JM. Psychometric properties of the Neck Disability Index and Numeric Pain Rating Scale in patients with mechanical neck pain. Arch Phys Med Rehabil 2008;89(1):69-74.

24. Kesiktas N, Ozcan E, Vernon H. Clinimetric properties of the Turkish translation of a modified neck disability index. BMC Musculoskelet Disord 2012;13:25.

25. Vernon $\mathrm{H}$, Mior $\mathrm{S}$. The neck disability index: a study of reliability and validity. J Manipulative Physiol Ther 1991;14(7):409-415.

26. Yakut E, Düger T, Oksüz Ç, et al. Validation of the Turkish version of the Oswestry Disability Index for patients with low back pain. Spine (Phila Pa 1976) 2004;29(5):581-585.

27. http://www.raosoft.com/samplesize.html., Access date: December 24, 2020.

28. Sun $P$, Lu X, Xu C, Sun W, Pan B. Understanding of COVID-19 based on current evidence. J Med Virol 2020;92(6):548-551.

29. Lechien JR, Chiesa-Estomba CM, De Siati DR, et al. Olfactory and gustatory dysfunctions as a clinical presentation of mild-to-moderate forms of the coronavirus disease (COVID-19): a multicenter European study. Eur Arch Otorhinolaryngol 2020;277(8):2251-2261.

30. Karaarslan F, Demircioğlu Güneri F, Kardeş S. Postdischarge rheumatic and musculoskeletal symptoms following hospitalization for COVID19: prospective follow-up by phone interviews. Rheumatol Int 2021;41(7):1263-1271.

31. Şahin T, Ayyildiz A, Gencer-Atalay K, Akgün C, Özdemir HM, Kuran B. Pain Symptoms in COVID-19. Am J Phys Med Rehabil 2021;100(4):307-312.

32. Soares FHC, Kubota GT, Fernandes AM, et al. Prevalence and characteristics of new-onset pain in COVID-19 survivours, a controlled study. Eur J Pain 2021;10.1002/ejp.1755.

33. Wang YX, Gou C, Peng TT, et al. Retrospective Analysis of Neurological Symptoms of Severe/Critical COVID-19 Patients in Sichuan Province. Sichuan Da Xue Xue Bao Yi Xue Ban 2020;51(6):873-877. 